\title{
A carreira na visão de repatriados: Um estudo de caso em uma multinacional brasileira do ramo da mineração
}

\author{
Paula Pacheco de Azevedo Guimarães ${ }^{1}$, \\ Denise Medeiros Ribeiro Salles e Victor Hugo Cabral Cruz Lontra
}

Universidade Federal Fluminense, Niterói, RJ, Brasil.

DETALHES DO ARTIGO
Histórico do artigo:
Recebido em 28 de abril de 2015
Aceito em 9 de outubro de 2015
Disponível online em 30 de abril de 2016
Sistema de Revisão "Double Blind Review"
Editor científico:
Eduardo Eugênio Spers

Palavras-chaves:

Expatriação

Repatriação

Carreira

\begin{abstract}
RESUMO
A internacionalização tornou-se realidade para muitas organizações, as quais enviam recorrentemente seus empregados para viver e trabalhar no exterior. No retorno, os repatriados podem não encontrar a concretização de suas expectativas, como a ascensão na carreira, gerando desmotivação e uma possível evasão, o que caracteriza o insucesso da expatriação. Sendo assim, este artigo objetiva analisar as expectativas e percepções dos repatriados sobre o crescimento na carreira e reconhecimento. Foi realizado estudo de caso em uma multinacional brasileira, tendo sido feitas onze entrevistas semi-estruturadas com repatriados, uma com membro da área de mobilidade global e pesquisa documental. Os dados foram tratados através da técnica de análise de conteúdo e observou-se que somente quatro repatriados obtiveram ascensão na carreira, contrariando as expectativas dos demais. Entretanto, quando se trata da percepção de reconhecimento, sete afirmaram sentir-se reconhecidos. Conclui-se que, embora esteja explícito um ausente planejamento de carreira dos repatriados, a sensação de reconhecimento denota confiança destes na organização. Nota-se, ainda, esperança de que as expectativas quanto ao futuro desenvolvimento na carreira sejam concretizadas, em algum momento, com o fim das consequências da crise econômica.
\end{abstract}

C 2016 Internext | ESPM. Todos os direitos reservados!

\section{Introdução}

A internacionalização crescente das organizações se tornou uma consequência da globalização. Implementação de novos negócios em mercados internacionais são exemplos de atuações estratégicas das organizações em se expandir e globalizar. Como prática desta expansão, a expatriação de empregados é conhecida como o envio de empregados para trabalhar em um país no exterior por um período de tempo (Dutra, 2002). Esta prática é muito usada pelas organizações por diversas razões, como para preencher posições técnicas, desenvolver lideranças e promover o desenvolvimento organizacional (Bonache et al, 2010; Tungli et al, 2009).

A implementação de operações internacionais estratégicas requer uma gestão internacional de recursos humanos $(\mathrm{GIRH})$, a qual é reconhecida como determinante para o sucesso ou fracasso da expatriação (Deresky, 2004). Além de adquirir experiência e crescimento pessoal e profissional, o que motiva o empregado a aceitar a designação é a expectativa de desenvolvimento de carreira (Martins, 2013). No momento da repatriação, poderá haver decepção do repatriado pela não concretização de suas expectativas, muitas vezes por falta de alinhamento entre estas e o planejamento da organização para o processo, gerando problemas tais como insatisfação, redução do comprometimento e improdutividade (Tanure et al, 2007). A análise das expectativas e percepções dos designados referentes ao crescimento na carreira, além do reconhecimento dado aos repatriados, é o objetivo deste estudo. 
O tema da repatriação ainda está emergindo nos estudos nacionais, sendo, muitas vezes, negligenciada pelas multinacionais (Gallon, 2011; Spohr, 2011). Assim, além da expatriação e suas etapas, este estudo explora o processo de preparação para o retorno do expatriado, sua readaptação cultural e profissional, bem como as causas de falhas da repatriação e suas consequências. Segundo Gallon (2011), o expatriado é enviado ao exterior com uma missão e atividades amplas, porém quando retorna ao país de origem, muitas vezes exerce as mesmas atividades ou outras similares anteriores à expatriação. Em alguns casos ocorre a inexistência de atividades específicas para o empregado qualificado pelo trabalho no exterior. Tal fato ratifica a necessidade de aprofundar o tema da repatriação e, assim, contribuir para a literatura focando na carreira dos repatriados. Este artigo parte do pressuposto de que a repatriação é ainda mal planejada pelas organizações que expatriam seus funcionários, com ausência de efetivo planejamento de carreira, o que acarreta dissonâncias nas expectativas de crescimento nas carreiras dos repatriados e de reconhecimento pela organização.

Visando o objetivo proposto, um estudo de caso foi realizado em uma multinacional brasileira, tendo sido realizadas onze entrevistas com repatriados, uma com membro da área de mobilidade global e pesquisa documental. Os dados foram analisados com base na técnica de análise de conteúdo.

A estrutura do artigo contempla a introdução, posteriormente há o referencial teórico abordando a gestão da expatriação, seguida pelo capítulo de repatriação e carreira. Em seguida, são apresentadas a metodologia, a caracterização da organização e a análise dos resultados. Por fim, apresentam-se as conclusões e contribuições do estudo, limitações e sugestões para pesquisas futuras e para a prática.

\section{Gestão da expatriação}

O acúmulo de capital da Era de Ouro do capitalismo, a abertura de mercado e a possibilidade de lucros elevados, tornou o mundo um cenário propício para a internacionalização de capital. Com isso, partes desses capitais foram alocadas em países da América Latina, Ásia e África através das multinacionais, promovendo um rápido processo de globalização econômica e modificações nas relações de trabalho. Precisava-se competir com concorrentes globais e se dedicar à internacionalização, seja pela aquisição de insumos ou pela expansão de suas operações. No Brasil, as organizações nacionais expostas à concorrência externa começaram a se movimentar no sentido da internacionalização a partir de 1990 (Orsi, 2010).

A importância de uma GIRH é crescente, vista a maior complexidade de operações internacionais e a necessidade de assegurar uma gestão com qualidade. Tal complexidade se deve a variedades culturais e legais de diversos países para os quais os expatriados são enviados (Champoux, 2011). A GIRH é considerada elemento fundamental da estratégia global de implementação de negócios e reconhecida como fator determinante de sucesso ou fracasso nas operações internacionais. Isto devido ao fato de ser a responsável por gerir as etapas da expatriação, tais como a seleção, o treinamento e suporte ao empregado (Deresky, 2004).

Em um cenário de constantes mudanças, a GIRH atua como parceiro estratégico, facilita o alcance dos objetivos organizacionais e possui um papel relevante para atrair, manter e desenvolver os expatriados. A complexidade dos negócios em contextos multinacionais exige maior sensibilidade da GIRH para lidar com diversidade e cooperação necessárias para o sucesso do processo de expatriação (Sousa, 2014).

Pode-se, assim, perceber a importância da GIRH, visto que, para a expatriação, são necessários funcionários qualificados com capacidades técnicas e entendimentos culturais para o devido suporte à estratégia de internacionalização da organização.

\subsection{Expatriação}

O expatriado é aquele que atuará por um período determinado ou de forma definitiva em um país diferente daquele no qual foi contratado para trabalhar (Dutra, 2002). Organizações decidem pela expatriação por variados motivos estratégicos, tais como: preencher posições não supridas pelos trabalhadores locais devido à falta de competências técnicas ou gerenciais; desenvolver lideranças; e abertura de unidades promovendo o desenvolvimento organizacional e possibilitando maior controle e coordenação da matriz, por meio da interação de seus processos e socialização de seus membros (Bonache et al, 2010; Tungli et al, 2009).

Espera-se que os expatriados, além da resolução dos problemas, gerem novos conhecimentos para a 
organização e/ou desenvolvam habilidades de liderança. Abandonar uma antiga visão restrita do mundo organizacional e dos negócios em prol de uma visão mais global possibilita uma maior compreensão das complexidades e especificidades de cada país, ajudando a desenvolver a capacidade de liderança e adequando, de forma mais efetiva, o negócio da organização. Vale ressaltar que nem todo funcionário enviado ao exterior possui abundante conhecimento a compartilhar ou características para se tornar uma futura liderança na organização. Desta forma, tornase importante o conhecimento prévio dos profissionais sobre o motivo pelo qual estão sendo expatriados e sobre a expectativa da empresa em relação ao seu trabalho e à sua carreira na organização (Black e Gregersen, 1999).

Segundo Tanure et al (2007), é importante que a expatriação seja vista como um processo com etapas interligadas para o seu sucesso. A primeira etapa do processo de expatriação corresponde à identificação da estratégia de internacionalização da organização, para que a expatriação seja devidamente conduzida pela GIRH.

A clareza do objetivo da expatriação compreende a segunda etapa. A transparência dos procedimentos do RH para lidar com possíveis divergências entre as expectativas da organização e do futuro expatriado sobre o processo de expatriação é crucial para todo o processo. Ou seja, as razões e objetivos da missão precisam estar claramente pactuados entre ambas as partes. Tal objetividade auxilia no bom resultado da seleção dos profissionais a serem expatriados, minimizando possíveis problemas no processo de repatriação.

A terceira etapa aborda a seleção dos candidatos à expatriação. Entre seus critérios, citam-se o conhecimento técnico e o desempenho na operação doméstica. Destaca-se que, entre as organizações brasileiras, é comum ser tomado como critério o nível de confiança depositado pela empresa no funcionário. Além de habilidades técnicas, segundo Freitas e Dantas (2011), é interessante o expatriado possuir capacidade e facilidade em se adaptar a diferentes culturas e situações desconhecidas. Entretanto, muitas vezes os processos de seleção deixam de valorizar tal critério. Mais algumas características de expatriados são associadas ao sucesso do processo: a capacidade de comunicação, o alto nível de sociabilidade, facilidade com idiomas, a orientação cosmopolita e a flexibilidade comportamental. A família também é vista como peça fundamental na seleção de um expatriado, devendo ter, igualmente, a sua opinião avaliada. 0 pouco apoio do cônjuge ou companheiro é apontado como fator de possível fracasso, já que tensões familiares ocasionam, em muitos casos, a falta de concentração no trabalho, tamanha é a pressão (Ivancevich, 2008).

Segundo Camara (2008), é importante que o potencial expatriado seja enviado ao possível país de destino a fim de conhecer e visitar as instalações e o novo ambiente. Isto minimizaria futuros imprevistos, em função da prévia interação entre o candidato e a cultura organizacional e local, caso a decisão seja favorável à transferência. A não aceitação, pelos candidatos, à proposta de transferência internacional pode gerar dúvida pela possibilidade da recusa representar futura estagnação ou mesmo regressão em suas carreiras (Martins, 2013).

Os principais fatores que motivam os futuros expatriados a aceitarem a missão são os benefícios financeiros, o conhecimento de novas culturas e os desafios pessoais e profissionais que thes serão proporcionados. Destaca-se, também, a expectativa que futuros expatriados possuem em termos de desenvolvimento na carreira e no seu reconhecimento pela organização. Muitos problemas gerados na repatriação são frutos de expectativas não correspondidas, especialmente aquelas relativas ao desenvolvimento na carreira organizacional (Tanure et al, 2007; Martins, 2013).

A quarta etapa, preparação e orientação dos candidatos, é vista como muito importante para a melhor ambientação no novo país de trabalho. Entretanto, o treinamento é negligenciado por muitas organizações, evidenciando um fator de possível insucesso da missão (Teixeira, Silva \& Lessa, 2011). O foco do treinamento está usualmente nas questões culturais e ambientais, para as quais são disponibilizadas ferramentas tais como livros, vídeos e até visitas programadas ao país de destino. No novo cotidiano do expatriado, será preciso que ele desenvolva e mantenha relações com atores diversos no país para onde será transferido. Por isso, é importante analisar, localizar e reconhecer potenciais problemas que surgirão devido a dificuldades ou imprevistos sobre tais relacionamentos (Deresky, 2004).

O adequado ajustamento e preparação do expatriado para viver em uma nova cultura são 
necessários para a redução do choque cultural. Este choque pode ser visto como um estado de desorientação, frustração e ansiedade resultante em não saber como agir em uma cultura pouco familiarizada (Finuras, 2011). O estresse familiar, a hostilidade com os locais e a improdutividade no trabalho podem ser resultados desse choque e causar o retorno precoce do expatriado, caracterizando um fracasso da missão e um consequente alto custo para a organização (Gallon et al, 2013; Kubo e Braga, 2013). Quando se transfere internacionalmente um executivo, a organização espera beneficiar-se das experiências e do aperfeiçoamento das qualificações do expatriado, como a melhoria das habilidades gerenciais, a ampliação da visão de mundo e do relacionamento interpessoal, incluindo o comando (DERESKY, 2004).

Segundo Ivancevich (2008), o processo de seleção é uma etapa complexa, crítica e capaz de encontrar um potencial expatriado de sucesso, diminuindo as chances de fracasso da expatriação. Ou seja, é essencial escolher o executivo certo para determinada função a ser desempenhada fora e seu adequado aperfeiçoamento técnico e cultural. Entretanto, para Deresky (2004), o treinamento não deve ser dado somente ao futuro expatriado, mas também à família que o acompanha. Tal preparação é requisitada devido ao familiar estar mais exposto à cultura local do que o expatriado, o qual está mais inserido na rotina dentro da organização. A família representa um elemento influenciador potente nas decisões do funcionário sobre a expatriação, bem como sobre o possível retorno precoce da missão, devendo, assim, sua adaptação ser reconhecida pela organização como alvo de preocupação e de ação planejada (Andreason, 2008; Martins, 2013).

Na quinta etapa é abordado o ajuste do papel do futuro expatriado na organização, situando-o cada vez mais sobre o processo. A sexta e a sétima etapas compreendem a gestão de desempenho dos expatriados e a remuneração, sendo ajustados os incentivos e benefícios oferecidos pela organização às necessidades e desempenho do expatriado. Uma adequada política de remuneração é essencial quando se tem a necessidade de atrair, manter e motivar os profissionais expatriados, visto que uma das motivações para os expatriados aceitarem a missão são os ganhos financeiros (Deresky, 2004; Martins, 2013).
A última etapa corresponde à repatriação, a qual é muitas vezes negligenciada (Spohr, 2011). Entretanto, esse complexo processo de retorno e readaptação possui um alto grau de importância para a organização e para o repatriado.

\section{Repatriação e carreira}

O profissional repatriado pode ser entendido como aquele que retorna da missão para o seu país de origem (Gallon et al, 2013). Esta fase de readaptação ao antigo habitual ambiente de trabalho é considerada tão importante e crítica quanto à fase de treinamento e aperfeiçoamento à nova cultura, efetuada nos primeiros momentos da expatriação. Pode-se entender a carreira como uma sequência de trabalhos executados e posições ocupadas durante a vida de uma pessoa, que estão repletas de expectativas, necessidades, aspirações individuais e imposições da organização e da sociedade. É fruto da relação entre o indivíduo e a organização, um elemento de conciliação dinâmica entre ambas as partes (Dutra, 2011).

A repatriação, se não desenvolvida adequadamente, coloca em risco um investimento realizado com o objetivo de trazer retorno com experiências e conhecimentos do expatriado. Vale ressaltar que não são muitas as organizações que possuem programas de repatriação. Os motivos alegados são a falta de profissionais especializados em programas deste tipo, seus elevados custos e, ainda, a falta do conhecimento sobre a importância e a necessidade destes programas. Ainda, é escassa a quantidade de consultorias especializadas em gestão de carreira internacional, fazendo com que as organizações assumam tal responsabilidade (Deresky, 2004; Domingues, 2011).

Segundo Black e Gregersen (1999), o insucesso das designações internacionais pode ser caracterizado pela pouca importância dada ao retorno do expatriado, o qual acredita que o sucesso de sua missão merece reconhecimento. Os repatriados desejam aplicar suas novas habilidades e conhecimentos em posições que requeiram suas experiências adquiridas através da expatriação, mas são muitas vezes desapontados pela indiferença da matriz em relação ao seu retorno e às suas novas atribuições. Ainda é comum encontrar repatriados que se enquadram em atribuições temporárias ou assumem funções antigas, assim não conseguem se adaptar às suas atribuições e posições, geralmente 
em nível inferior às ocupadas anteriormente à expatriação e diferentes das que desempenharam no exterior, com maior independência (Freitas, 2006 e Gallon, 2011). Com isso, tais funcionários enfrentam dificuldades como desmotivação, sentimento de abandono e incertezas quanto a sua carreira e sua continuidade na organização.

O choque cultural reverso é algo comum em casos de falha na repatriação do funcionário. Ele pode ser entendido como a desorientação e dificuldade em se readaptar e se reinserir na organização. Entretanto, não é somente o repatriado a se sentir deslocado; a família, mais especificamente o cônjuge, também poderá apresentar dificuldades em se restabelecer, tanto profissionalmente quanto em suas relações sociais. Outras consequências de uma inadequada prática de repatriação são as expectativas não correspondidas em relação à carreira dos repatriados, gerando imagem negativa da expatriação e podendo ocasionar o desestímulo aos futuros candidatos (Deresky, 2004; Gallon et al, 2013).

Um programa de repatriação adequado que alcance os resultados esperados é aquele que se inicia antes do início da missão. O desenvolvimento de políticas e planejamentos condizentes à expatriação é fundamental. É importante que os funcionários percebam que a organização considera tais missões como parte do desenvolvimento de carreira e que valoriza corretamente as qualificações dos repatriados. A organização deve ter objetivos que reflitam nos seus planos de longo prazo, no compromisso e na recompensa visando ao benefício do expatriado (Deresky, 2004).

A fim de evitar a perda de conhecimentos, experiências e habilidades desenvolvidas no exterior pelo expatriado e de melhor aproveitá-las, as organizações devem adotar práticas importantes referentes à repatriação. Um programa formal de repatriação é um investimento que disponibiliza tutoria, treinamento intercultural e estruturação de um plano de carreira aos repatriados, otimizando as chances da organização de reter estes profissionais. Contudo, a falta deste programa pode prejudicar a readaptação da família, trazer consequências financeiras à organização, elevar índice de turnover e reduzir a produtividade. Ao questionarem o custo de tais medidas, organizações que enxergam a repatriação como ponto crítico para o sucesso da missão consideram tais gastos não significativos comparativamente aos benefícios da retenção de profissionais com experiência e visão global. Organizações que se encontram há mais de dez anos no mercado exterior já prezam e incluem a repatriação em suas políticas de carreira internacional (Black e Gregersen, 1999; Domingues, 2011; Spohr, 2011).

A repatriação deve ser reconhecida como parte do processo de desenvolvimento do expatriado. Entretanto, para muitos repatriados, este é um momento de desordem profissional e pessoal. Há a carência de um planejamento efetivo para a etapa da repatriação, a qual não é dada tanta criticidade, diferentemente do que ocorre com o momento da ida do funcionário para o exterior. Organizações que reconhecem a importância desse momento auxiliam os repatriados providenciando orientação de carreira e permitindo colocar em prática no trabalho suas experiências internacionais. Um planejamento da carreira do repatriado com antecedência à sua volta se faz importante, visto que uma falha neste item pode corroborar com a desmotivação do funcionário e sua consequente saída da organização. (Black e Gregersen, 1999; Domingues, 2011; Gallon et al, 2013, 2014).

Verifica-se que todo o processo de expatriação engloba práticas que se reforçam a todo o tempo, e sua adequada gestão se torna fundamental para o sucesso tanto da missão internacional como do desenvolvimento da carreira do repatriado.

\section{Metodologia}

A pesquisa buscou analisar as expectativas e as percepções que os repatriados têm a respeito do que é feito em relação ao seu desenvolvimento na carreira e ao reconhecimento que é dado a eles. $\mathrm{O}$ caráter qualitativo adotado permite compreender crenças, atitudes e motivações referentes ao comportamento dos entrevistados em específicos contextos sociais (Gaskel, 2002).

Em julho de 2013, foram realizadas onze entrevistas semi-estruturadas com repatriados e uma com um membro da área de mobilidade global, além de pesquisa documental. As entrevistas abertas tiveram auxílio de um roteiro de perguntas dispostas de maneira cronológica, organizadas por conceitos de pré-expatriação, expatriação e repatriação. A seleção para realização das entrevistas foi feita através da rede de relacionamento dos pesquisadores e de indicações de outros repatriados. 
Foi utilizado como critério para participar da pesquisa ser brasileiro; ter sido expatriado do Brasil por tal multinacional estudada; ter permanecido na missão por, no mínimo, seis meses; e ter sido repatriado há, no máximo, quatro anos. A técnica de análise dos dados utilizada foi a análise de conteúdo, a qual permite interpretação de dados através de técnicas de análise e procedimentos sistemáticos (Bardin, 2009).

\section{Caracterização da organização}

A pesquisa foi feita em uma organização multinacional brasileira do ramo da mineração, reconhecida como a maior produtora de minério de ferro, estando presente em mais de 30 países. Com mais de 60 anos de atuação e um histórico de destaques em termos de produção e lucro, a organização se viu, entretanto, nos anos 2008 e 2012, em meio à necessidade de diminuir seus investimentos e reduzir custos. Isto se deveu à desaceleração da economia global, à menor demanda mundial e à queda da cotação do minério de ferro.

Seu programa de expatriação é alinhado às estratégias organizacionais. Dentre as razões para designações internacionais destacam-se: preencher posições estratégicas; atender à falta de competência técnica ou de gestão; e desenvolver empregados com potencial. Buscam-se, no potencial expatriado, conhecimentos técnicos adequados para o perfil do cargo, visão global e mobilidade. O funcionário selecionado passa por um processo consistido em três fases. A primeira fase é a pré-designação, que compreende preparação, auxílio e orientação aos futuros expatriados; a segunda fase diz respeito à alocação no país de destino; e, com o fim da designação, o empregado regressa ao país de origem, caracterizando a repatriação.

Em termos de carreira, a informação obtida é a de que "a empresa envidará os seus melhores esforços para encontrar um cargo adequado no país de origem" (Instrução De Mobilidade Global, 2011, p.15). Não foram encontradas informações referentes à disponibilização de treinamento de readaptação para os repatriados, cuja existência também foi negada pela entrevistada da área de mobilidade global.

\section{Apresentação e análise dos resultados}

A fim de analisar os resultados obtidos, a técnica baseada em Bardin (2009) permitiu a organização do conteúdo das entrevistas em oito categorias com seus respectivos códigos, conforme a Tabela 1 . Tais categorias foram definidas com base na literatura, relacionadas ao objetivo da pesquisa, caracterizando a grade de análise como grade fechada. A divisão das categorias está disposta cronologicamente, facilitando a análise. Através das categorias formuladas, é possível ter a definição do perfil dos entrevistados, assim como entender o processo da expatriação, o que é essencial para alcançar o objetivo do estudo, explorando a repatriação e sua relação com a carreira.

Tab. 1

Categorias e códigos

\begin{tabular}{|l|}
\hline 1) PERFIL DO ENTREVISTADO \\
\hline Gênero \\
\hline Idade \\
\hline Estado civil \\
\hline Filhos \\
\hline País de destino \\
\hline Tempo na organização \\
\hline Tempo da expatriação \\
\hline Tempo de retorno \\
\hline
\end{tabular}

\section{2) PRÉ-EXPATRIAÇÃO}

Seleção

Motivo da aceitação

Expectativas em termos de carreira

Possibilidade de recusa

Clareza do objetivo da missão

Treinamento cultural

Sensação de preparo

Fonte: Autores

\section{3) ADAPTAÇÃO}

Adaptação cultural

Adaptação profissional

Possível antecipação do retorno

\begin{tabular}{|l|}
\hline 4) PERSPECTIVA DO TRABALHO \\
\hline Objetivo da missão \\
\hline Comunicação com a unidade de origem \\
\hline Remuneração e benefícios \\
\hline Acompanhamento da organização \\
\hline
\end{tabular}

\section{5) PRÉ-REPATRIAÇÃO}

Motivo da volta

Planejamento do futuro posto

Preocupação antes da volta
6) READAPTAÇÃO

Treinamento de readaptação

Readaptação cultural

Readaptação profissional

\begin{tabular}{|l|}
\hline 7) CARREIRA \\
\hline Função antes $X$ Função depois \\
\hline Percepção sobre a carreira \\
\hline Reconhecimento \\
\hline
\end{tabular}

\section{8) BALANÇO}

Aspectos positivos

Aspectos negativos 


\subsection{Perfil do entrevistado}

A partir dos dados obtidos com a pesquisa, é possível constituir um perfil do repatriado, evidenciado na Tabela 2. aumentar as chances de sucesso (Ivancevich, 2008). É observado que nove expatriados foram selecionados por convites por parte de superiores, como gerentes e diretores. Ainda, houve dois casos

Tab. 2

Perfil dos entrevistados

\begin{tabular}{ccccccccc}
\hline Entrevistado & País de destino & Gênero & Idade & $\begin{array}{c}\text { Estado } \\
\text { civil }\end{array}$ & Filhos & $\begin{array}{c}\text { Tempo na } \\
\text { organização }\end{array}$ & $\begin{array}{c}\text { Duração da } \\
\text { expatriação }\end{array}$ & $\begin{array}{c}\text { Período desde o } \\
\text { retorno }\end{array}$ \\
\hline E1 & Omã & F & 31 & Solteira & Não & 4 anos & 1 ano e 6 meses & 1 ano e 5 meses \\
\hline E2 & Austrália & M & 25 & Solteiro & Não & 4 anos e 10 meses & 6 meses & 3 meses \\
\hline E3 & China & M & 29 & Solteiro & Não & 5 anos & 2 anos & 3,5 anos \\
\hline E4 & China & M & 49 & Casado & Não & 9 anos & 3,5 anos & 6 meses \\
\hline E5 & África do Sul & M & 29 & Solteiro & Não & 3 anos e 4 meses & 1 ano e 8 meses & 9 meses \\
\hline E6 & Omã & M & 40 & Casado & Sim & 8 anos & 5 anos & 3 semanas \\
\hline E7 & Omã e Malásia & F & 32 & Solteira & Não & 4 anos & 2,5 anos & 4 meses \\
\hline E8 & Malásia & M & 32 & Casado & Não & 8 anos & 2 anos & 7 meses \\
\hline E9 & Malásia & M & 30 & Casado & Não & 3 anos & 6 meses & 1 ano e 10 meses \\
\hline E10 & Omã & M & 40 & Casado & Sim & 4 anos & 5 anos & 3 semanas \\
\hline E11 & Malásia & F & 31 & Casado & Não & 4 meses & 8 meses & 1 ano e 7 meses \\
\hline
\end{tabular}

Fonte: Autores

Com base nos dados da Tabela 2, observa-se que os entrevistados tinham entre 25 e 49 anos quando foram expatriados. Em sua maioria, são do sexo masculino, casados e sem filhos. Tais dados se aproximam da ideia de Ferraz (2011) que associa o perfil do expatriado ao gênero masculino, casado, sem filhos e com média de 35 anos. Vale ressaltar que todos os casados, com exceção do entrevistado 8, foram acompanhados de suas esposas, as quais eram a favor da expatriação.

Os países com mais destino foram Malásia e Omã, seguidos de China, África do Sul e Austrália. Em relação ao tempo na organização, os entrevistados tinham de quatro meses a nove anos. A duração da expatriação variou entre seis meses e cinco anos, e o tempo desde o retorno à organização teve variações de três semanas a três anos e meio.

\subsection{Pré-expatriação}

O primeiro ponto a ser explicitado é a seleção para a expatriação, em que foi abordado como surge a oportunidade e a forma como se escolhe o designado. Eleger as pessoas certas é necessário para em que os expatriados participaram do processo seletivo por iniciativa própria.

Em relação ao motivo para aceitar a designação, a oportunidade em encarar um desafio pessoal e profissional foi a razão mais abordada pelos entrevistados, observado em sete relatos, demonstrando serem profissionais preocupados em viver experiências complexas que os desenvolvam. Foram também apontadas, em quatro casos, expectativas em termos de avanço de carreira como motivador da ida. A oportunidade em ampliar os horizontes e obter fluência no idioma também foram razões indicadas por três vezes. Em duas situações, a aceitação ocorreu por representar uma oportunidade para a família em morar no exterior, e para outros dois repatriados, uma "oportunidade única" por não terem filhos ou serem solteiros. O enriquecimento curricular também foi registrado em dois relatos.

Quando perguntados sobre as expectativas em termos de carreira como fruto da sua designação, observou-se que sete repatriados esperavam um desenvolvimento na carreira decorrente da expatriação. Isto evidencia o fato de muitos 
empregados aceitarem a missão esperando esse avanço (Martins, 2013).

A recusa da expatriação, dependendo da cultura organizacional, pode representar um retrocesso nas carreiras dos empregados pelo fato da organização não receber bem a negação (Martins, 2013). Entretanto, de acordo com os entrevistados, não foi percebida possibilidade de demissão pela negação à proposta.

Quanto ao conhecimento do objetivo da expatriação, nove entrevistados afirmaram terem clareza do propósito da missão. Tal clareza, segundo Tanure et al (2007), é um fator importante para o sucesso da designação internacional. Entretanto, observaram-se dois relatos que demonstram que, mesmo obtendo clareza do planejado antes da missão, quando se encontra já no local de destino, o expatriado pode sentir-se em dúvida quanto aos detalhes do objetivo e sua real aplicação, havendo possibilidade do planejado não sair como esperado.

O treinamento cultural possibilita ao profissional se ambientar melhor no país de destino. Se negligenciado, torna-se um fator de insucesso da missão (Teixeira, Silva e Lessa, 2011). Neste caso, foi disponibilizado, para todos os designados, um treinamento cultural, inclusive para os acompanhantes dos expatriados casados. Isto apoia a ideia de Deresky (2004), que defende o treinamento também para os familiares, já que estes estão mais expostos ao cotidiano do país de destino e possuem considerável influência sobre os expatriados. Para nove entrevistados, tal treinamento foi útil como preparação para a expatriação. Entretanto, em dois casos o treinamento cultural não foi visto como eficaz. Segundo entrevistados, as aulas foram consideradas fracas e poderiam, inclusive, ser desconsideradas, já que o seu conteúdo era lido de um livro, o que poderia ser feito pelo próprio expatriado. Embora esses dois casos demonstrem uma falha pontual, verificou-se que, na maioria dos casos, o treinamento foi bem avaliado pelos empregados. Esta etapa é considerada de fundamental importância ao ajudar a reduzir o choque cultural (Deresky, 2004).

Quando questionados sobre a sensação de preparo para a expatriação, seis entrevistados afirmaram se sentirem preparados. Dois entrevistados, porém, negaram tal sensação e três repatriados alegaram que existiam desafios que só seriam conhecidos estando no país de destino. Isto pode ser explicado por Tanure et al (2007), que defendem que o treinamento cultural deve ser feito antes da expatriação como também após o início da missão, considerando-se as novas visões e recentes experiências.

\subsection{Adaptação}

A adaptação à nova cultura é um fator importante, já que é, também, causa de insucessos de missões, segundo Black e Gregersen (1999). No entanto, isto pode ser evitado com uma eficaz preparação. Observou-se que sete entrevistados não sentiram dificuldades de adaptação no país de destino, demonstrando que a adaptação cultural não foi um problema para eles. Entretanto, três entrevistados fizeram menção ao idioma local, como o inglês australiano e o mandarim e um entrevistado mencionou a cultura diferente, representando adversidades.

Sobre a adaptação ao novo ambiente de trabalho, ninguém sentiu dificuldades em se adaptar, tanto em relação às suas atribuições quanto aos seus colegas de trabalho. Há relatos que evidenciam a receptividade dos funcionários locais e, também, dos expatriados que lá já se encontravam.

Em relação à possível antecipação do retorno ao país de origem, a interrupção da expatriação pode ser uma consequência de uma equivocada adaptação do expatriado ao local de destino, segundo Kubo e Braga (2013), seja pelo idioma, por questões culturais ou pela não adaptação ao novo ambiente de trabalho. Entretanto, sete entrevistados não pensaram em retornar antes do tempo previsto. Somente em dois relatos pode-se observar que esta ideia surgiu em algum momento pontual e em dois casos houve o retorno, de fato, devido a questões pessoais.

\subsection{Perspectiva do trabalho}

Ao verificar os objetivos das designações, oito dos onze entrevistados tinham como missão o desenvolvimento e estruturação de um novo projeto ou negócio, caracterizando uma designação com importância e de caráter estratégico. Isto evidencia a ideia de Gallon (2011), de que um expatriado, durante sua designação, muitas vezes atua em atividades ou projetos importantes e estratégicos para a organização, com devida autoridade.

Um fator importante para a expatriação é a interação da organização com o designado, mesmo a 
distância. Observou-se que sete entrevistados não se sentiram isolados e participavam das discussões com os empregados do Brasil, demonstrando interface com a unidade de origem. Apenas quatro entrevistados alegaram não participar das discussões por estarem mais focados no projeto. Entretanto, é interessante a organização estar atenta a tal afastamento para que não seja potencializador de uma possível dificuldade de reintegração social na repatriação.

Quando questionados sobre a remuneração e os benefícios, e se estes compensavam as dificuldades em estarem longe de casa, oito entrevistados afirmaram que sim. Isto evidencia que uma política de boa remuneração e bons benefícios é fundamental quando se tem o intuito de atrair, manter e motivar o expatriado na missão, já que os benefícios financeiros são uma das principais razões para o aceite do funcionário à expatriação (Deresky, 2004; Martins, 2013). Três repatriados, entretanto, afirmaram que a remuneração e os benefícios recebidos durante a expatriação não foram fatores críticos para eles, demonstrando indiferença.

Sobre a atenção dada pela organização à adaptação dos expatriados, dez repatriados alegaram não ter recebido um acompanhamento da unidade de origem, tendo os empregados locais desempenhado o papel de suprir esta falta. Vale ressaltar que houve divisão de opiniões referente à falha desse acompanhamento. Enquanto seis entrevistados relataram omissão da unidade de origem em dar apoio e acompanhamento, quatro alegaram acreditar que, caso precisassem, a área de mobilidade global atenderia aos expatriados. Observa-se uma carência de proatividade da GIRH quanto ao acompanhamento dos expatriados.

\subsection{Pré-repatriação}

A decisão do regresso à unidade de origem também foi abordada nesta pesquisa, a fim de entender melhor os motivos pelos quais se deu a volta do empregado. Observaram-se sete casos em que a volta já estava previamente definida e os expatriados retornaram na data prevista. Por outro lado, foram observados dois casos em que, devido à crise que afetou a organização, alguns projetos foram desmobilizados e dois entrevistados retornaram ao Brasil, inesperadamente. Já em dois casos, questões pessoais motivaram os expatriados a interromper a duração prevista, demonstrando influência da vida pessoal na vida profissional. Vale ressaltar que oito dos entrevistados demonstraram vontade de ter permanecido mais tempo no exterior. Dos três que negaram esta vontade, é interessante observar um relato que expressa a relação entre o lado pessoal e o profissional. Segundo o entrevistado E5, o grande desafio da expatriação seria encontrar o equilíbrio entre a situação profissional e a pessoal do funcionário. Em seu caso, a vida pessoal estava ficando muito comprometida e, então, foi tomada a decisão de voltar à unidade de origem, embora houvesse, por parte da organização, a manifestação da vontade de manter o entrevistado na missão.

Antes da volta do expatriado à unidade de origem, é importante o planejamento do posto a ser ocupado por ele, alinhando suas expectativas de carreira às diretrizes de desenvolvimento da organização, demonstrando, assim, preocupação em aproveitar as experiências obtidas (Black e Gregersen, 1999; Domingues, 2011; Gallon et al, 2013, 2014). Pode-se perceber, através dos relatos que, anteriormente à expatriação, não houve qualquer planejamento sobre a carreira do empregado após a missão. No entanto, próximo à sua volta, observou-se, em oito casos, conversas sobre os futuros cargos a serem ocupados. Entretanto, é relevante analisar que foi questionável a qualidade desta discussão dissociada de um planejamento anterior e cujos resultados, em muitos casos, foram influenciados pela conjuntura econômica.

Após ter vivido no exterior e ter se distanciado da unidade de origem, o momento da volta, muitas vezes, representa grande preocupação para os repatriados. Sete repatriados confirmaram tal sentimento, motivados pela preocupação da readaptação, seja cultural, pessoal ou profissional, esta última em meio à conjuntura de crise internacional influenciando a organização.

\subsection{Readaptação}

O momento de retorno do expatriado pode não representar uma feliz volta para casa se a repatriação não for vista como parte importante do processo da expatriação. Seja profissional, pessoal ou cultural, a falha na readaptação pode causar diversos problemas para o repatriado (Gallon et al, 2013). Pode-se citar o choque cultural reverso, o qual é uma possível consequência da falta de atenção na readaptação do repatriado e demonstra que práticas, como o treinamento ou programa de readaptação, 
poderiam evitar tal problema (Deresky, 2004). Entretanto, é possível observar que não foi disponibilizado um treinamento de readaptação aos repatriados. Ainda assim, dez entrevistados não relataram significativos problemas para se readaptarem a cultura brasileira. Houve apenas um caso em que a entrevistada demonstrou resistência à readaptação cultural.

Já a readaptação profissional abrange aspectos relacionados às novas atribuições e ao relacionamento com os colegas de trabalho. O repatriado tem de se acostumar com suas novas funções, às vezes muito diferentes da função exercida na expatriação (Gallon, 2011), além de se relacionar com outros profissionais que não o acompanharam na missão e não têm ideia de como se dá o processo de readaptação após um tempo fora da organização (Black e Gregersen, 1999). É possível observar que oito repatriados se adaptaram às funções e à organização sem dificuldades. Em três casos houve desconforto; um devido à falta de reconhecimento e outros dois devido a enorme discrepância entre a unidade de origem e a de onde foi realizada a expatriação.

Foi visto que apenas três repatriados conseguiram aplicar o que aprenderam na missão, como o melhor uso da língua inglesa, evidenciando o não aproveitamento, por parte da organização, das novidades que o repatriado está disposto a implementar. Já em relação aos relacionamentos com seus colegas de trabalho, oito repatriados alegaram ter se adaptado bem, alguns recebendo apoio e reconhecimento.

\subsection{Carreira}

A fim de analisar o avanço na carreira dos repatriados, foi realizado um quadro comparativo dos seus cargos antes e depois da expatriação, conforme a Tabela 3.

Pode-se observar que, de fato, houve avanço na carreira de apenas quatro entrevistados (E3, E4, E9 e E10). Entretanto, vale ressaltar que o entrevistado E10 alegou que, durante a expatriação, havia sido promovido a gerente e, portanto, quando retornou ao Brasil, foi demovido à função de especialista. Também identificou-se que, para cinco repatriados (E1, E2, E5, E8, E11), não houve avanço na carreira, permanecendo nos mesmos níveis hierárquicos. Ainda, o entrevistado E6 foi rebaixado e a entrevistada E7 ficou sem posição na organização quando retornou, sendo designada novamente para expatriação em outra localidade. Com estes resultados, é possível observar que somente uma pequena parte dos repatriados teve um real crescimento na carreira. É importante que a organização tenha adequados planos para os repatriados procurando não desmotivá-los, e que os façam perceber que considera suas experiências como parte de seu desenvolvimento de carreira (Deresky, 2004; Gallon et al, 2013).

Tab. 3

Cargos

\begin{tabular}{ccc}
\hline Entrevistado & $\begin{array}{c}\text { Função antes da } \\
\text { expatriação }\end{array}$ & $\begin{array}{c}\text { Função após a } \\
\text { repatriação }\end{array}$ \\
\hline E1 & Analista & Analista \\
E2 & Analista & Analista \\
E3 & Analista & Gerente de área \\
E4 & Gerente geral & Diretor \\
E5 & Analista & Analista \\
E6 & Coordenador & Engenheiro \\
E7 & Gerente & Sem posição \\
E8 & Gerente & Gerente \\
E9 & Analista & Supervisor \\
E10 & Analista & Especialista \\
E11 & Advogada & Analista \\
\hline
\end{tabular}

Fonte: Autores

Além da questão do real avanço na carreira dos entrevistados, a percepção dos repatriados sobre o que foi efetivamente feito em prol de suas carreiras é muito relevante. Tal percepção é importante para corresponder às expectativas possíveis e criar a imagem de que a designação internacional não está relacionada a retrocesso de carreira (Deresky, 2004; Gallon et al, 2013). Sete entrevistados perceberam que a expatriação não foi favorável ao crescimento na carreira, reconhecendo a inexistência de políticas efetivas, por parte da organização, para tal desenvolvimento, mesmo que isso tenha ocorrido devido à situação desfavorável em que a empresa se encontrava em relação aos seus negócios e mercado.

O reconhecimento organizacional percebido pelo repatriado também foi um fator relevante a ser destacado nesta análise. Segundo Black e Gregersen (1999), os repatriados acreditam que o sucesso de sua missão merece reconhecimento. Tal reconhecimento atrelado a um avanço de carreira é o que os expatriados esperam quando aceitam a missão (Tanure et al, 2007; Martins, 2013). Entretanto, pode-se observar que a questão do reconhecimento esteve bem dividida. Embora a 
maioria tenha percebido que a expatriação não caracterizou um avanço na carreira, sete dos onze entrevistados afirmaram sentir-se reconhecidos pela organização, ou seja, todos os promovidos e três não promovidos. É interessante observar que estes últimos, mesmo não ascendendo em posições na carreira, se sentiram reconhecidos também. Pelo menos, até o momento.

Vale destacar que a maior parte dos repatriados não promovidos (quatro dos sete) creditaram a não ascensão à conjuntura econômica desfavorável. Contudo, ainda possuem esperança em avançarem na carreira posteriormente. Como exemplo, os entrevistados E5 e E7 afirmaram não terem percebido ações efetivas para o desenvolvimento nas carreiras devido à situação da organização naquele momento, e que, se tivessem retornado em outro cenário, a história seria diferente. Já no que se refere ao reconhecimento, consideraram-se reconhecidos pela organização.

A falta de reconhecimento percebido por alguns repatriados evidencia uma falha na repatriação desses empregados. O momento da repatriação deve ser administrado com cuidado e primar pela clareza da informação ao empregado sobre a importância do esforço dispensado na sua missão e de sua consequente valorização profissional. Caso contrário, pode-se causar desmotivação e evasão (Black e Gregersen, 1999; Domingues, 2011; Gallon et al, 2013, 2014)

\subsection{Balanço}

Após toda a experiência vivida pelos repatriados, é interessante conferir o balanço que os entrevistados fizeram das suas expatriações, seja no âmbito profissional, pessoal ou familiar. Os fatores positivos observados nos relatos abrangem: razões pessoais, como amadurecimento; profissionais, como enriquecimento; e familiares, como aproximação com seus entes. Em relação a fatores negativos, os motivos alegados foram a distância e a decepção pela forma como a repatriação foi tratada pela organização. Apesar dos fatores críticos apontados, foi demonstrado pelos entrevistados que o balanço da expatriação foi mais positivo do que negativo. Assim, quando questionados sobre a possibilidade de "voltar no tempo", todos os entrevistados foram enfáticos em afirmar que aceitariam novamente a designação internacional.

\section{Conclusão}

Este estudo objetivou analisar as expectativas e percepções dos repatriados de uma multinacional quanto ao avanço das suas carreiras e ao seu reconhecimento.

Observou-se que a preparação do expatriado para a designação, com treinamentos culturais, foi útil e trouxe sensação de preparo para os funcionários. Da mesma forma proveitosa foi a adaptação no país de destino, tanto do ponto de vista cultural quanto profissional. Vê-se que estas primeiras etapas do processo da expatriação não representaram pontos de dificuldades, embora sejam fatores críticos para o sucesso da designação.

Foi possível perceber que, durante o período da expatriação, as designações se caracterizaram de considerável importância por serem estratégicas e por terem o objetivo de desenvolvimento de algum novo projeto/negócio no país de destino. Observouse, quanto à comunicação com áreas da sede, não ter havido problemas, caracterizando uma relevante integração. A remuneração e os benefícios também apresentaram aprovação por parte de muitos entrevistados, compensando possíveis dificuldades. Entretanto, verificou-se a inexistência de um acompanhamento efetivo, por parte da organização, dos expatriados e do processo de expatriação, sendo, muitas vezes, esta falta suprida pelos locais. Caracterizou-se, portanto, como falhos os fatores de monitoramento e de demonstração de apoio durante a designação do empregado, por parte da organização.

Ao se analisar a preparação para a volta do expatriado ao país de origem, sete entrevistados voltaram devido ao fim do prazo previsto de designação. Dois entrevistados retornaram por questões pessoais e outros dois entrevistados devido a ordens da organização, que atuava na época da pesquisa, em um cenário conturbado, gerando preocupação quanto à repatriação. Foi verificado que, anteriormente à expatriação, não houve qualquer plano sobre a carreira dos funcionários após a designação. Já antes de voltar, houve conversas da organização com os futuros repatriados sobre a posição em que iriam ser alocados no retorno, entretanto, esta discussão teve sua qualidade e seus resultados questionados pelos entrevistados. Notase uma ausência de um efetivo planejamento de carreira dos repatriados, comprometendo a etapa da repatriação a qual deve ser dada atenção. 
A readaptação do empregado ao local de origem não foi acompanhada de treinamentos de auxílio. Entretanto, mesmo não havendo tais ações, é interessante notar que a maior parte dos repatriados alegou ter se readaptado bem, cultural e profissionalmente.

Quanto ao desenvolvimento na carreira, apesar dos repatriados esperarem um avanço advindo da sua experiência internacional, não foi percebida uma ação efetiva da organização na maioria dos casos, ocasionando decepções nos entrevistados. Vale a reflexão sobre o alinhamento entre expectativas dos repatriados e as futuras ações da organização em relação a essas. Vê-se que um bem-sucedido planejamento é importante para ambas as partes: o bem estar do funcionário e a permanência deste na organização, visto que a frustração pode influenciar no desempenho e motivação do repatriado, culminando em sua saída da organização e a perda dos investimentos realizados neste profissional. Entretanto, é possível observar que, ainda assim, muitos se sentiram reconhecidos, inclusive por acreditarem que avançarão na carreira quando a conjuntura econômica desfavorável que influencia a organização passar. Tal credulidade denota confiança na organização e esperança na concretização de suas expectativas em algum momento.

A repatriação é um assunto em crescente exploração na literatura. Entretanto, ainda carece de maiores investigações, visto que é uma complexa etapa da expatriação relacionada à estratégia da organização. Portanto, os resultados deste estudo visam contribuir para o campo da Administração por explorar a gestão da expatriação e, principalmente, a etapa da repatriação e sua relação com a carreira em uma importante multinacional brasileira reconhecida por sua grande internacionalização. Ademais, a pesquisa oferece reflexões acerca de como a carreira dos repatriados deve ser gerenciada, já que é um fator preponderante nas expectativas presentes em todo o processo da expatriação.

Sobre as limitações da pesquisa, pode-se citar o tamanho da amostra, visto que seria desejável um maior número de entrevistados para corroborar com uma análise mais aprofundada no caso. Ademais, não houve representatividade de repatriados desligados da organização. Desta forma, as pesquisas futuras poderiam abranger tal público, registrar suas manifestações discursivas e progredir na análise. No âmbito prático, sugere-se a existência de um planejamento de carreira elaborado antes da expatriação, com o propósito de deixar claro para o designado o que a organização pretende em termos de ascensão de funções após a repatriação, visando reduzir possíveis frustrações no regresso.

\section{Referências}

- ANDREASON, A. (2008) Expatriate adjustment of spouses and expatriate managers: An integrative research review. International Journal of Management, 25(2), 382-395.

- BARDIN, L. (2009) Análise de conteúdo. Lisboa: Edições 70.

- BLACK, J.; GREGERSEN, H.; MENDENHALL, M. (1999) The right way to manage expats. Harvard Business Review, mar./abr., p. 52-62.

- BONACHE, J., BREWSTER, C., SUUTARI, V., DE SAÁ, P. (2010) Expatriation: Traditional criticisms and international careers: introducing the special issue. Thunderbird International Business Review, 52 (4) p. 263-274. DOI: 10.1002/tie.20349.

- CAMARA, P. (2008) Gestão de pessoas em contexto internacional. Publicações Dom Quixote, 7- 263.

- CHAMPOUX, J. (2011) Organizational Behaviour Integrating Individuals, Groups, and Organizations. Fourth Edition. New York and London: Routledge.

- DERESKY, H. (2004) Administração global: estratégia e interpessoal. Porto Alegre: Ed. Bookman.

- DOMingues, C. (2011) Políticas de carreiras para o gestor internacional - um estudo em empresas brasileiras internacionalizadas. Tese (Doutorado). Fundação Getúlio Vargas, BRA.

- DUtRA, J. (2002) Gestão de pessoas. Modelo, Processos, Tendências e Perspectivas. São Paulo: ATLAS.

- DUTRA, J. (2011) Administração de carreira. Uma proposta para repensar gestão de pessoas. São Paulo: Atlas.

- FERRAZ, S. (2011) Estarão os expatriados portugueses satisfeitos com a expatriação? Dissertação (Mestrado) Universidade Católica Portuguesa, Portugal.

- FINURAS, P. (2011) Gestão Intercultural: Pessoas e Carreiras na Era da Globalização. 3a Edição. Lisboa: Sílabo.

- FREITAS, M. (2006) Expatriação de Executivos. GV EXECUTIVO, 5(4), set./out. 
- $\quad$ FREITAS, M.; DANTAS, M. (2011) O Estrangeiro e o novo grupo. Revista de Administração de Empresas, 51(6), 601-608. http://dx.doi.org/10.1590/S003475902011000600008.

- GALLON, S. (2011) Repatriação e carreira: possibilidades e desafios. Dissertação (Mestrado em Administração) - Universidade Federal do Rio Grande do Sul-UFRGS, BRA.

- GAlLON, S.; SCHEFFER, A.; BITENCOURT, B. (2013) Eu fui, voltei e ninguém viu: um estudo sobre a expectativa de carreira após a repatriação em uma empresa brasileira. Cadernos EBAPE.BR, 11 (1), p. 128-148.

- gallon, S.; SCHEFFer, A.; BItenCOURT, B. A EXPATRIAÇÃO E O SEU PAPEL ESTRATÉGICO NAS EMPRESAS INTERNACIONALIZADAS (2014) Internext - Revista Eletrônica de Negócios Internacionais, 9 (3), p. 38-56.

- instrução de mobilidade globAl (2011) Documento interno.

- IVANCEVICH, J. (2008) Gestão de Recursos Humanos. 10. ed. São Paulo: Mcgrawhill.

- KUBO, E.; BRAGA, B. (2013) Ajustamento intercultural de executivos japoneses expatriados no Brasil: um estudo empírico. Revista de Administração de Empresas, 53 (3), p. 243-255.

- MARTINS, D. (2013) Gestão e Retenção de Repatriados: um estudo empírico em empresas portuguesas. 1a edição, Madrid: Bubok Publishing S. L.

- ORSI, A. (2010) Gestão internacional de pessoas: políticas de recompensas para executivos expatriados por empresas brasileiras. 2010. Tese (Doutorado em Administração) - Universidade de São Paulo-USP, BRA.

- SPOHR, N. (2011) o processo repatriação na visão de profissionais repatriados brasileiros. Dissertação (Mestrado) - Fundação Getúlio Vargas - FGV.

- SOUSA, A. (2014) A adaptação intercultural da família: um estudo exploratório com expatriados portugueses. Dissertação (Mestrado) - Instituto Politécnico do Porto, Portugal.

- TANURE, B; EVANS, P; PUCIK, V. (2007) A gestão de pessoas no Brasil. Virtudes e Pecados Capitais. Estudos de Caso. Rio de Janeiro: ELSEVIER.

- TEIXEIRA, L.; SILVA, J.; LESSA, L. (2011) Executivos brasileiros expatriados: percepções da nova função e influência da distância psíquica. REDES, 16 (1) p. 19-38. DOI: http://dx.doi.org/10.17058/redes.v16i1.917

- TUNGLI, Z., PEIPERL, M. (2009) Expatriate practices in German, Japanese, UK, and US multinational companies: a comparative survey of changes. Human Resource Management, 48 (1), p. 153-171. DOI: 10.1002/hrm.20271

\section{Sobre os autores}

- Paula Pacheco de Azevedo Guimarães é Mestranda no Programa de Pós-Graduação em Administração na Universidade Federal Fluminense - UFF, Niterói, RJ, Brasil.E-mail: ppaguimaraes@gmail.com

- Denise Medeiros Ribeiro Salles é Doutora em Administração pela Fundação Getúlio Vargas EBAPE/FGV/RJ. Também é Professora Adjunto no Mestrado Acadêmico em Administração e no Mestrado Profissional em Sistemas de Gestão da Universidade Federal Fluminense - UFF, Niterói, RJ, Brasil.E-mail: denisesalles@id.uff.br

- Victor Hugo Cabral Cruz Lontra é Mestre no Programa de Pós-Graduação em Administração na Universidade Federal Fluminense - UFF, Niterói, RJ, Brasil.E-mail: vlontra@gmail.com 


\title{
A career in the view of repatriates: A case study in a Brazilian mining multinational
}

Paula Pacheco de Azevedo Guimarães, Denise Medeiros Ribeiro Salles and Victor Hugo Cabral Cruz Lontra

Fluminense Federal University, Niteroi, RJ, Brazil.

\begin{tabular}{l}
\hline ARTICLE DETAILS \\
\hline Article history: \\
Received 28 april 2014 \\
Accepted 9 october 2014 \\
Available online in 30 april 2016 \\
Double Blind Review System \\
Scientific Editors \\
Eduardo Eugênio Spers \\
\hline Keywords: \\
Expatriation \\
Repatriation \\
Career
\end{tabular}

\begin{abstract}
Internationalization has become a reality for many organizations that recurrently send their employees to live and work abroad. On their return, repatriates may not have their expectations fulfilled in terms of career accession, resulting in demotivation and possible evasion, which characterizes the failure of expatriation. This article aims to analyze repatriates' expectations and perceptions of career growth and recognition in a mining company. The case study was performed in a Brazilian multinational, with eleven semistructured interviews with returnees and a member of the area of global mobility and documental research. The data were processed through the technique of content analysis, where it is noted that only four repatriated obtained growth in their career after returning, contrary to expectations. However, when it comes to the perception of recognition, seven stated feeling recognized. It is concluded that although a career plan for the repatriates is explicitly missing, the feeling of recognition denotes confidence in the organization. Hopes and expectations about their future development and career fulfillment were also noted, be it at some point after the economic crisis.
\end{abstract}

(C) 2016 Internext | ESPM. All rights reserved! 